\title{
AEROBIC BACTERIAL ISOLATES FROM BURN WOUND INFECTION PATIENTS AND THEIR ANTIMICROBIAL SUSCEPTIBILITY PATTERN IN KOTA, RAJASTHAN.
}

Naveen Saxena'1, Divya Dadhich², Deepak Maheshwari³.

1. Associate Professor, Department of Microbiology, Government Medical College, Kota.

2. Post Graduate Resident, Department of Microbiology, Government Medical College, Kota.

3. Post Graduate Resident, Department of Microbiology, Government Medical College, Kota.

\author{
CORRESPONDING AUTHOR \\ Dr. Naveen Saxena, \\ Department of Microbiology, \\ Government Medical College, Kota. \\ Email-drnaveen_saxena@yahoo.co.in
}

\section{HOW TO CITE THIS ARTICLE:}

Naveen Saxena, Divya Dadhich, Deepak Maheshwari. "Aerobic Bacterial isolates from burn wound infection patients and their antimicrobial susceptibility pattern in Kota, Rajasthan." Journal of Evolution of Medical and Dental Sciences 2013; Vol2, Issue 23, June 10; Page: 4156-4160.

ABSTRACT:- INTRODUCTION: Infection is a major cause of morbidity and mortality in burn patients, in spite of considerable advances in burn wound care and medical treatment. Burn wound infections are largely nosocomial in origin, incidence and isolation differ from hospital to hospital, study of isolates and their antibiogram is necessary to provide adequate and effective treatment that will reduce morbidity and mortality of patients. OBJECTIVE: The present study was undertaken to know the aerobic bacteriological profile of burn wound infection and their antimicrobial susceptibility pattern. MATERIAL AND METHOD: A total of 209 specimens were received from burn patients between January to July 2012. Wound swabs were taken with aseptic precautions by disposable sterile swabs. These swabs were transported to central laboratory where they were cultured on blood agar and MacConkey agar and incubated aerobically overnight at $37^{\circ} \mathrm{C}$. Isolates were identified based on standard microbiological methods and antimicrobial susceptibility testing was done by Kirby Bauer's disc diffusion method. RESULT: A total of 147 bacterial pathogens were isolated from 209 samples. The most frequent cause of infection was found to be Pseudomonas aeruginosa (48.3\%), followed by Staphylococcus aureus (19.29\%), Escherichia coli (13.26\%), Klebsiella spp. (8.44\%), Proteus spp. (3.7\%), Enterococcus spp.(6 \%) \& Citrobacter spp. (1\%). High level of drug resistance was observed for Cefotaxime, Ceftazidime and Cotrimoxazole among gram negative pathogens. Imipenem, Piperacillin/Tazobactam, Amikacin and Ciprofloxacin were found to be most effective. Twenty two percent of the Staphylococcus aureus isolates were methicillin resistant but none was resistant to Vancomycin \& Linezolid. CONCLUSION: Pseudomonas aeruginosa is a major cause of infection in burn wounds which showed high level resistance to antimicrobials. The high prevalence of antimicrobial resistance emphasizes the need for strengthening the infection control practices and regular and periodical surveillance activities to contain the upward trend of resistance. Isolation pattern and antibiogram 
from burn patients of this study provides guidelines for adequate and effective antibiotic treatment that will reduce morbidity and mortality of patients.

KEY WORDS: Burn wound infection Antimicrobial susceptibility testing

INTRODUCTION: Burn wounds are highly susceptible to colonization \& infection by microorganisms and this is a major problem in the management of burn victims. ${ }^{1}$ Infected burn wounds are not only associated with a delay in epidermal maturation and deep scar formation but also prolongs the hospital stay of the patient and increases the chances of mortality due to sepsis, when compared to non-infected patients. ${ }^{2}$ Most of the burn victims, who survive including the initial 24 hours after burns, succumb to burn infection and its complications. Immediately following the thermal injury, the burn wounds are sterile; but eventually get Colonized with microorganisms. ${ }^{3}$ Staphylococci that are present deep within sweat glands and hair follicles colonize the wound surface within the first 48 hours. After 5-7 days, the GNB and yeast derived from the host's normal GI flora, upper respiratory tract and the hospital environment get transferred to the wounds through: vectors, such as health care workers. ${ }^{4}$ Various factors responsible are disruption of the skin barrier, a large cutaneous bacterial load, the possibility of the normal bacterial flora becoming opportunistic pathogens and severe depression of the immune system. All these factors contribute towards the sepsis in a burn victim..$^{5}$ Despite various advances in infection control measures, like early detection of microorganisms and newer and broad spectrum antibiotics, management of burn septicemia still remains a big challenge and septicemia continues to be the leading cause of death in burn patients. ${ }^{6}$ It is now estimated that about $75 \%$ of the mortality following burn injuries is related to infections rather than osmotic shock and hypovolemia. ${ }^{7}$ The pattern of infection differs from hospital to hospital; the bacterial flora of infected wound may change considerably during the healing period. ${ }^{8}$ Emergence of multi drug resistant pathogens in hospital setting has seriously constrained the available therapeutic options. This necessitates periodic review of the isolation pattern and study of antibiogram of the isolates to strengthen surveillance activities. The present study was undertaken to know the antimicrobial susceptibility profile of various bacterial isolates recovered from patients of infected burn wounds which will help in instituting empirical therapy and minimize irrational use of antimicrobial agents.

MATERIAL AND METHOD: After taking ethical clearance from: Institutional Ethics Committee, this study was conducted in the Department of Microbiology at the central Laboratory of Government Medical College, Kota (Rajasthan). A total of 209 specimens were received from burn patients between January to July 2012 . The patients with $50 \%$ burn were enrolled in this study. Wound swabs were taken with aseptic precautions using disposable sterile swabs. All samples were collected and processed after obtaining informed consent from patients and the samples were immediately transferred to the central laboratory where they were processed.

These samples were cultured on blood agar and MacConkey agar and incubated aerobically overnight at $37^{\circ} \mathrm{C}$. The Isolates were identified based on standard microbiological methods including culture, staining and biochemical tests. ${ }^{9}$ The antimicrobial susceptibility testing of the isolates was carried out by Kirby Bauer disc diffusion method ${ }^{10}$ using commercially available antimicrobial discs procured from the HiMedia Laboratories Pvt. Ltd., Mumbai. Sensitivity result was interpreted according to National Committee of Clinical Laboratory Standard (NCCLS). ${ }^{11}$ 
RESULT: A total of 147 bacterial pathogens were isolated from 209 samples. The most frequent cause of infection was found to be Pseudomonas aeruginosa (48.3\%), followed by Staphylococcus aureus (19.29\%), Escherichia coli (13.26\%), Klebsiella spp. (8.44\%), Proteus spp. (3.7\%), Enterococcus spp. (6\%) \& Citrobacter spp.(1\%).(Table 1) A High level of drug resistance was observed for Cefotaxime, Ceftazidime and Cotrimoxazole among gram negative pathogens. Piperacillin/Tazobactam, Amikacin and Ciprofloxacin were found to be most effective.(Table 2) Twenty two percent of the S. aureus isolates were methicillin resistant but none was resistant to Vancomycin \& Linezolid.(Table 3)

DISCUSSION: In our study, Pseudomonas aeruginosa was the commonest organism isolated, accounting for $48.3 \%$ of the total isolates, followed by the Staphylococcus aureus (19.29\%). Our observations were in accordance with Yildirim et al,12 Zorgani et al ${ }^{13}$ and Wonkeun Songa et al. ${ }^{14}$ We noted a significantly high percentage of resistance among gram-negative bacilli to Ceftazidime, Cefotaxime and Cotrimoxazole. This alarming trend was seen for both Enterobacteriaceae group and for Pseudomonas aeruginosa. Resistance among the Gram-negative bacilli was, in general, least to Imipenem, Amikacin, Ciprofloxacin and Piperacillin/Tazobactam. Twenty two percent Staphylococcus aureus were found to be methicillin resistant. However Vancomycin and Linezolid were shown to be $100 \%$ effective. Staphylococcus aureus was highly resistant to Erythromycin \& Co-trimoxazole. This was in accordance with Kehinde AO et al. ${ }^{15}$

This high antimicrobial resistance is probably promoted due to selective pressure exerted on bacteria due to numerous reasons like non adherence to hospital antibiotic policy and excessive and indiscriminate use of broad-spectrum antibiotics. These multi drug resistant strains establish themselves in the hospital environment in areas like sinks, taps, railing, mattress, toilets and thereby spread from one patient to another.

CONCLUSION: Pseudomonas aeruginosa is a major cause of infection in burn wounds which showed high level resistance to antimicrobials. Amikacin, Imipenem, Ciprofloxacin and combination drugs like Piperacillin/Tazobactam were found to be effective for Gram negative organisms hence could be used for empirical therapy. Vancomycin \& Linezolid (100\%) were found to be most effective drugs for Gram positive organisms. The high prevalence of antimicrobial resistance emphasizes the need for strengthening the infection control practices and regular and \& periodical surveillance activities to contain the upward trend of resistance.

This study concludes that in vitro testing prior to antibiotic use may help in the prevention and treatment of multi-drug resistant pathogens in burn infection. Isolation pattern and antibiogram of burn wound of this study provides adequate and effective treatment that will reduce morbidity and mortality of patients. 


\section{ORIGINAL ARTICLE}

TABLE 1: The distribution of bacterial isolates from infected burn wounds

\begin{tabular}{|l|l|}
\hline Organisms & Total no. $\mathrm{n}=147$ \\
\hline Pseudomonas aeruginosa & $71[48.3 \%]$ \\
\hline Staphylococcus aureus & $28[19.29 \%]$ \\
\hline Escherichia coli & $19[13.26 \%]$ \\
\hline Klebsiella spp. & $12[8.44 \%]$ \\
\hline Proteus spp. & $06[3.7 \%]$ \\
\hline Enterococcus spp. & $10[6 \%]$ \\
\hline Citrobacter spp. & $01[1 \%]$ \\
\hline
\end{tabular}

TABLE 2: Antimicrobial susceptibility pattern of Gram negative isolates

\begin{tabular}{|l|l|l|l|l|l|}
\hline $\begin{array}{l}\text { Antimicrobial } \\
\text { agent }\end{array}$ & $\begin{array}{l}\text { Pseudomonas } \\
\text { aeruginosa (71) }\end{array}$ & $\begin{array}{l}\text { Escherichia } \\
\text { coli (19) }\end{array}$ & $\begin{array}{l}\text { Klebsiella } \\
\text { spp. (12) }\end{array}$ & $\begin{array}{l}\text { Proteus } \\
\text { spp. (06) }\end{array}$ & $\begin{array}{l}\text { Citrobacter } \\
\text { spp. (01) }\end{array}$ \\
\hline $\begin{array}{l}\text { Piperacillin/ } \\
\text { Tazobactam }\end{array}$ & 62 & 15 & 09 & 04 & 01 \\
\hline Ceftazidime & 49 & 13 & 09 & 03 & 01 \\
\hline Cefotaxime & NT & 10 & 07 & 02 & 01 \\
\hline Imipenem & 68 & 19 & 10 & 05 & 01 \\
\hline Amikacin & 64 & 18 & 10 & 05 & 01 \\
\hline Ciprofloxacin & 60 & 16 & 09 & 05 & 01 \\
\hline TMP+SMX & NT & 11 & 08 & 03 & 01 \\
\hline
\end{tabular}

NT $=$ Not tested

TMP+SMX = Trimethoprim, Sulphamethoxazole

TABLE 3: Antimicrobial susceptibility pattern of Gram positive isolates

\begin{tabular}{|l|l|l|}
\hline Antimicrobial agent & Staphylococcus aureus (28) & Enterococcus spp (10) \\
\hline Erythromycin & 18 & $\mathrm{R}$ \\
\hline Cotrimoxazole & 19 & $\mathrm{R}$ \\
\hline Ceftriaxone & 23 & $\mathrm{R}$ \\
\hline Ciprofloxacin & 26 & $\mathrm{R}$ \\
\hline Amikacin & 26 & $\mathrm{R}$ \\
\hline Clindamycin & 24 & $\mathrm{R}$ \\
\hline Cefoxitin & 22 & $\mathrm{R}$ \\
\hline Vancomycin & 28 & 10 \\
\hline Linezolid & 28 & 10 \\
\hline
\end{tabular}

$\mathrm{R}=$ Resistant

\section{REFERENCES:}

1. Macedo JLS de, Santos JB. Bacterial and fungal colonization of burn wounds . Memórias do Instituto Oswaldo Cruz . scielo ; 2005. p. 535-9. 
2. Singer AJ, McClain SA. Persistent wound infection delays epidermal maturation and increases scarring in thermal burns. Wound Repair and Regeneration. Blackwell Science Inc; 2002 Nov $1 ; 10(6): 372-7$.

3. Church D, Elsayed S, Reid O, Winston B, Lindsay R. Burn wound infections. Clinical microbiology reviews [Internet]. 2006 Apr 1 [cited 2013 Apr 8];19(2):403-34. Available from: http://cmr.asm.org/cgi/content/long/19/2/403

4. Altoparlak, U., S. Erol, M. N. Akcay, F. Celebi, and A. Kadanali. The time-related changes of anti-microbial resistance patterns and predominant bacterial profiles of burn wounds and body flora of burned patients. Burns.2004; 30: 660-64.

5. Jones WG, Minei JP, Barber a E, Rayburn JL, Fahey TJ, Shires GT. Bacterial translocation and intestinal atrophy after thermal injury and burn wound sepsis. Annals of surgery [Internet]. 1990 Apr;211(4):399-405.

6. Bang RL, Gang RK, Sanyal SC, Mokaddas E, Ebrahim MK. Burn septicaemia: an analysis of 79 patients. Burns [Internet]. 1998 Jun;24(4):354-61.

7. Donati L, Scamazzo F, Gervasoni M, Magliano A, Stankov B, Fraschini F. Infection and antibiotic therapy in 4000 burned patients treated in Milan, Italy, between 1976 and 1988. Burns [Internet]. 1993 Aug;19(4):345-8.

8. Rajput A, Singh K, Kumar V. Antibacterial resistance pattern of aerobic bacteria isolates from burn patients in tertiary care hospital. Biomedical ... [Internet]. 2008 [cited 2013 May 10];19(1):1-4. Available from: http://biomedres.org/journal/pdf/250.pdf

9. Baron EJ, Peterson LR, Finegold SM (Eds). Conventional and rapid microbiological methods for identification of bacteria and fungi, Chapter 10. In: Bailey \& Scott's Diagnostic Microbiology, 9th ed. (Mosby) 1994:97.

10. Bauer AW, Kirby WM, Sherris JC, Turck M. Antibiotic susceptibility testing by a standardized single disk method. Am J Clin Pathol. 1966 Apr;45(4):493-6

11. Performance Standards for Antimicrobial Disk Susceptibility Test, CLSI. Vol. 28 No. 1, Jan. 2008.

12. Yildirim S, Nursal TZ, Tarim A, Torer $\mathrm{N}$ et al. Bacteriological profile and antibiotic resistance: comparison of findings in a burn intensive care unit, other intensive care units, and the hospital services unit of a single center. J Burn Care Rehabil. 2005; 26 (6):488-92.

13. Zorgani A, Zaidi M, Franka $\mathrm{R}$ et al.The pattern and outcome in a burns intensive care unit. Burns and Plastic Surgery Hospital, Tripoli, Libya. Annals of Burns and Fire Disasters 2002;15(4):179

14. Song W, Lee KM, Kang HJ, Shin DH, Kim DK. Microbiologic aspects of predominant bacteria isolated from the burn patients in Korea. Burns. 2001 Mar;27(2):136-9.

15. Kehinde AO, Ademola SA, Okesola AO, Oluwatosin OM, Bakare RA. Pattern of bacterial pathogens in burn wound infections in Ibadan, Nigeria. Ann Burns Fire Disasters. 2004;18:12-5. 